\title{
CONCOMITANT DERMOID CYSTS OF CONUS MEDULLARIS AND CAUDA EQUINA
}

\author{
Asdrubal Falavigna ${ }^{1}$, Orlando Righesso ${ }^{2}$, Alisson Roberto Teles ${ }^{3}$
}

Spinal dermoid cysts are benign tumors that results from congenital or adquired ectodermal inclusions ${ }^{1-7}$. Histologically they are characterized by the presence of dermal structures. These tumors account for $0.8 \%-1.1 \%$ of all primary spinal tumors with the majority occurring in the extramedullary or subdural juxtamedullary lumbosacral region, usually in the conus or cauda equina ${ }^{1,7}$. In the pediatric population, the prevalence of dermoid tumors is much greater, with dermoids accounting for $5 \%$ to $17 \%$ of all intradural lesions in reported series ${ }^{1,2,6}$. A higher incidence of dermoid cysts has been described in patients with spina bifida, dermal sinuses, myelomeningocele, hemi-vertebrae and syringomyelia ${ }^{1-4,6,7}$.

We present a rare case of an adult woman who presented with two separated dermoid cysts in the cauda equina and conus medullaris. The literature concerning to dermoids is also reviewed focusing on the tumor etiopathogenesis.

\section{CASE}

A 35-year-old woman presented with chronic low back pain and left ciatalgia. She had previous history of two abdominal surgeries to the treatment of chronic constipation with intraoperative diagnosis of intestinal adherences. No history of spinal trauma, surgery or lumbar puncture was reported. She brought a normal lumbar radiography. Neurological examination revealed hypoesthesia in the lateral surface of the left leg, weakness on dorsiflexion of the left foot and Lasègue sign on the left leg. The magnetic resonance imaging (MRI) evidenced a large mass located at cauda equina and a smaller mass located at the conus medullaris (Fig 1).

Surgical resection was accomplished through a posterior midline incision exposing L2 to S2. Dissection and lateral removal of musculature were performed followed by laminectomy from L3 to S1. There was a decrease of the epidural fat and the dural sac was hypertense and non-pulsatil. After opening the dura mater a large brown-yellowish tumor was observed tightly adhered with cauda equina nerves (Fig 2A). Microscopically to- tal tumor removal was accomplished with normal nervous margins (Figs 2B and 2C). A small fragment of the intradural conus tumor was resected and then the remaining tumor was excised by aspiration with the ultrasonic aspirator. The surgical time was 2.5 hours and the bleeding was $650 \mathrm{~mL}$.

The histological examination of the tumors in cauda equina and conus yielded a diagnosis of dermoid cysts (Fig 3). Postoperatively, the patient had urinary retention which reverted in two months. Follow-up at four years showed complete resolution of preoperative symptoms, including constipation, and no evidence of local or systemic recurrence.

\section{DISCUSSION}

Spinal dermoids are rare, accounting for $0.8 \%$ to $1.1 \%$ of all spinal tumors ${ }^{1,7}$. They are usually located in the lumbosacral region, with few cases reported in the thoracic

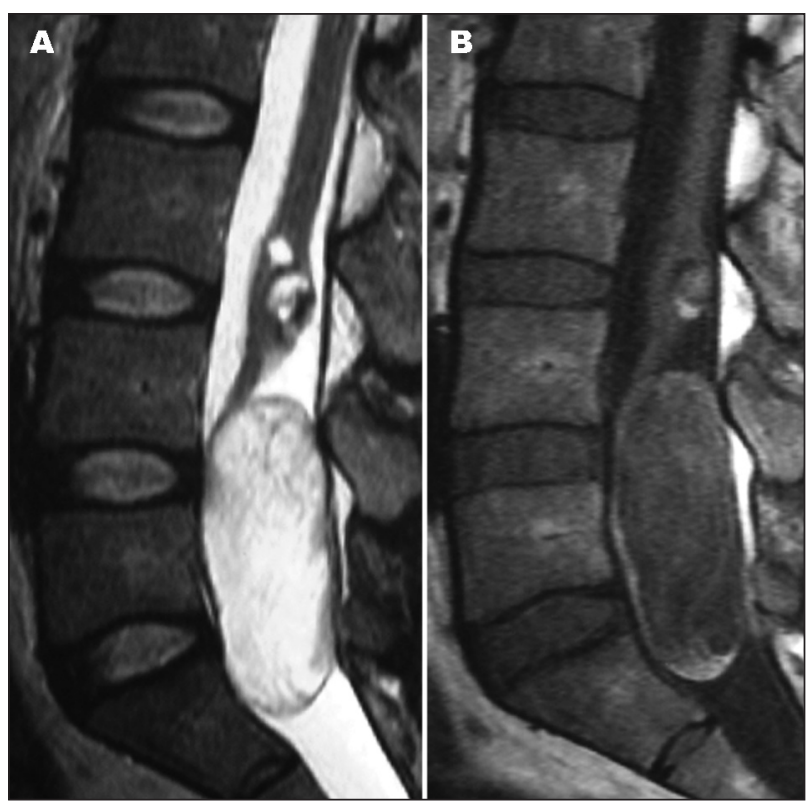

Fig 1. MRI sagittal sections. [A] T2-weighted and [B] T1-weighted sequences showing the cysts in the cauda equina and conus medullaris.

\section{CISTOS DERMÓIDES CONCOMITANTES DE CONE MEDULAR E CAUDA EQÜINA}

'Professor of Neurology and Neurosurgery, University of Caxias do Sul, Caxias do Sul RS, Brazil; ${ }^{2}$ Orthopedist, Caxias do Sul RS, Brazil; ${ }^{3}$ Medical student, University of Caxias do Sul, Caxias do Sul RS, Brazil

Received 13 August 2008, received in final form 18 November 2008. Accepted 9 February 2009.

Dr. Asdrubal Falavigna - Rua General Arcy da Rocha Nóbrega 401 / 602 - 95040-290 Caxias do Sul RS - Brasil. E-mail: asdrubal@doctor.com 


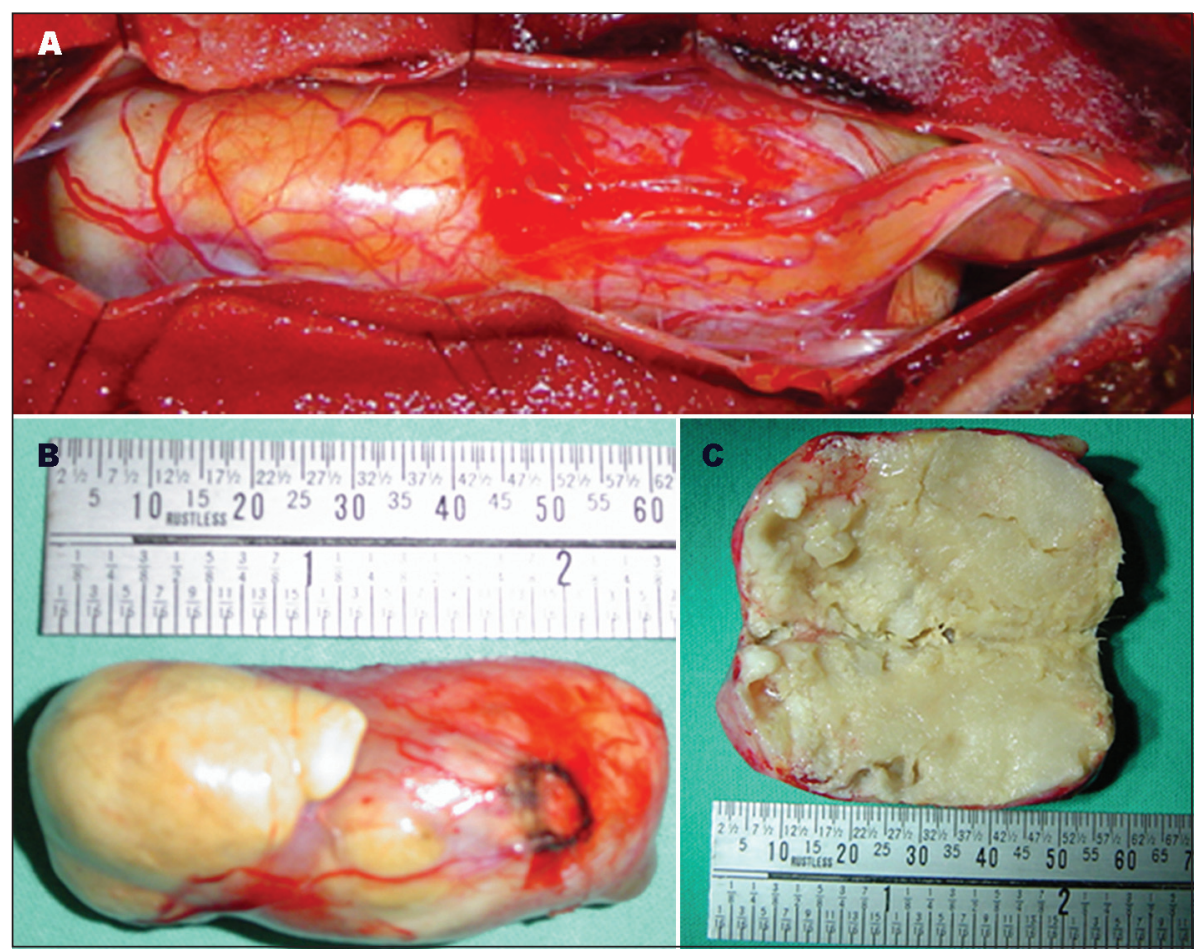

Fig 2. [A] Intraoperative visualization of the cauda equina tumor tightly adhered with the nerves. [B-C] Brown-yellowish cyst measuring $5.5 \times 3.5 \times 1.5$ centimeters.

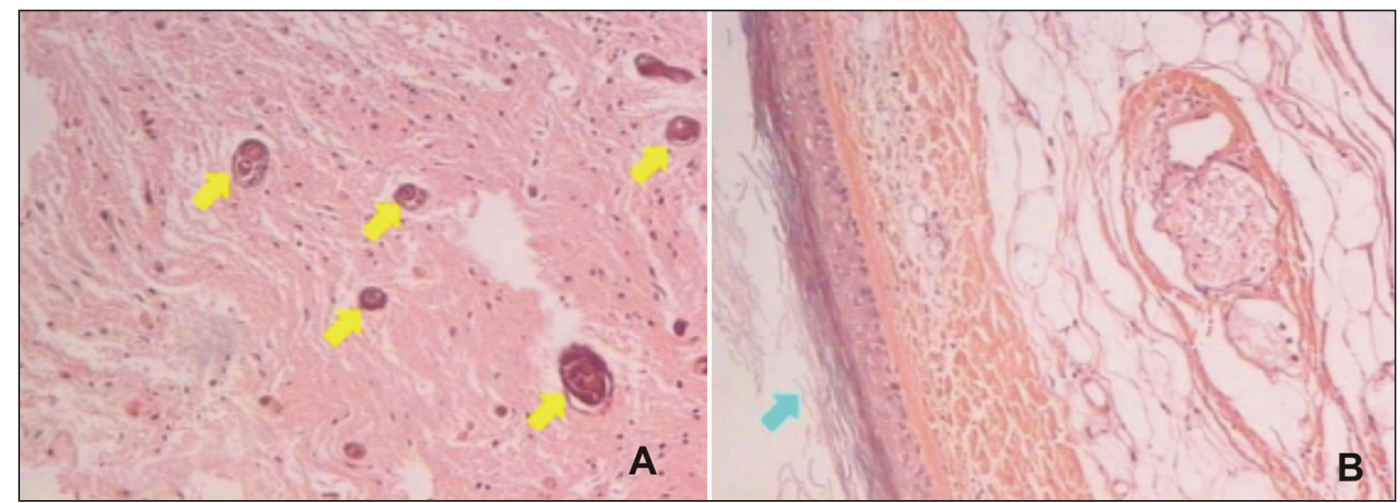

Fig 3. Histological analysis of the specimens. [A] Abundant cellular keratin debris and calcifications (arrows). [B] The cyst was covered by keratinized stratified squamous epithelium (arrow) (hematoxylin-eosin, original magnification $\times 10$ ).

and cervical spine ${ }^{1-4,6-8}$. In a series of 62 intradural conus and cauda equina tumors, Mathew and Todd ${ }^{9}$ reported 11 cases of dermoids (17\%), 9 epidermoids (14.5\%), 3 teratomas (5\%) and 3 lipomas (5\%), with these congenital midline tumors compounding $41 \%$ of the tumors. The extramedullary location is much more common that the intramedullary. In a series of 12 dermoids, Arseni et al.' reported that eight of them were extramedullary, three intramedullary and one in the coccygeal region. The association with other congenital spinal abnormalities is frequent ${ }^{1,2,4,6-8}$.

According to their origin, the dysembriogenic spinal tumors are classified in epidermoid, dermoid, theratoid or teratoma ${ }^{4}$. The epidermoids are derived from the epithe- lium tissue, without dermal structures, while dermoids, in addition to the epiderm, present with hair, sebaceous glands and other skin appendages. The theratoids have tissue from two germinative layers and teratomas from all the three.

Some theories have been proposed to explain the origin of dermoids. In 1897, von Bostroem ${ }^{10}$ proposed that between the third and fifth weeks of fetal development, cells fated for cutaneous ectoderm somehow become trapped within neural ectoderm during neural tube closure and eventually form tumors. According to this theory, the timing of the event (early or late) determine cell potentiality, which in turn determines the type of tumor 
(teratoma or dermoid or epidermoid) that will form. The predilection for poles of the neuroaxis, in particular the caudal end, is in some way related to the fact that poles are the last segments of the neural tube to close. In 1933, Holmdahl" attempted to connect the high incidence of lumbosacral lesions to his discovery that the caudal spine formed not from ectoderm but from a distinct, undifferentiated cell mass belonging to no particular germinal layer. Because cells from these lumbosacral precursors were less differentiated than ectoderm, he postulated that they were more likely to form tumors with pluripotentiality. In fact, nowadays it is known that ectodermal cells can revert to form cells of other germinal layers. Otherwise, Slooff ${ }^{\prime 2}$ stated that teratomas, dermoids and epidermoid cysts of the neuroaxis arise from cells whose position is correct but that somehow fail to receive the correct differentiation signals. On the other hand, some authors have demonstrated that dermoids can be also adquired lesions. Van Gilder and Schwartz ${ }^{13}$ produced dermoids experimentally in young rats by implantation of skin fragments. This theory was supported in human beings by other authors that reported the occurrence of such tumors secondary to implantation of dermal fragments into spinal subarachnoid space by accidental trau$\mathrm{ma}^{14}$, lumbar puncture ${ }^{15}$ or surgery ${ }^{16}$.

Our case is interesting because the adult patient with chronic low back and leg pain and intestinal dysfunction presented with two distinct dermoids located at the lumbosacral region. The patient had no history of spinal manipulation or trauma and any sign of dysraphism on physical and image exams. Its known that spinal dermoid cysts can rupture, and their content can spread throughout the subarachnoid space and ventricular system ${ }^{3,5}$. These cases may present with hydrocephalus, meningitis, spinal arachnoiditis or be asymptomatic ${ }^{3,5}$. The rupture can be spontaneously, posttraumatic or postoperatively ${ }^{3,5}$. It is possible that, in the case presented, the large extramedullary tumor of the cauda equine might have ruptured and implanted at the conus medullaris. Despite of the image exams apparently do not show major signs of rupture in our case, Calabrò et al. ${ }^{3}$ also reported a case with the same image pattern presenting with intraventricular implantation of the lipidic components. Other theory is that the two tumors resulted from two different embriogenic cells implantations in the same topography, without direct relation between the two dermoids. This possibility appears to be more acceptable because there was no major signs of cyst rupture and because the two dermoids were well encapsulated, without relation amongst themselves at surgical time.

Although a diagnosis cannot be made without a tissue sample, certain neuroimaging findings are characteristic and useful in helping to distinguish inclusion cysts from other more common spinal lesions. MRI is the modality of choice for diagnosis of dermoid tumors ${ }^{3}$. These inclusion cysts can be differentiated from intrinsic glial tumors of the cord on the basis of the heterogeneity of the T1- or T2-weighted signal, lack of contrast enhancement, and signal characteristics with lipid content. When lesional imaging characteristics are suggestive of an inclusion cyst, careful review of imaging studies may reveal subtle abnormalities in the osseous spine or adjacent soft tissue either as a response to slow tumor growth or as a result of imperfect midline fusion during development. The differential diagnosis of dermoid cysts on imaging includes lesions with high lipid content such as teratomas and lipomas ${ }^{8,9}$.

The dermoid cyst is usually filled with a soft, whitish yellow waxy substance with hairs and glandular secretions in addition to areas of induration ${ }^{1,2,4,6}$. This substance is produced by the secretion of sebaceous glands, progressive desquamation of the epithelium and the transformation of keratin into fatty acids and cholesterol. Histologically, these tumors are usually surrounded by a multi-layered, cornified epithelium, with a collagen stroma, lying in the dermis and hypodermis with cutaneous appendages, such as hair follicles, hair, sebaceous and sweat glands, as well as sebum ${ }^{1,2,4,6}$. Calcifications can also be observed in the cyst content ${ }^{1}$. Blood vessels usually are detected only in the connective tissue surrounding the tumor and they do not penetrate the epithelial wall of the dermoid'.

Given the indolent, benign nature of these tumors, some authors state that asymptomatic lesions should be managed conservatively ${ }^{2,6}$. In addition, radical removal is, at times, precluded by the risk of neurological deficit in cases where tumor capsule adheres tightly to nervous tissue. In these patients, some authors have recommended clinical observation until tumor re-growth gives rise to novel symptoms ${ }^{1,2,6}$, which will happen in a small percentage of patients with long-term follow-up ${ }^{7}$. In fact, most cases of spinal dermoids cannot be totally excised, as demonstrated in many surgical series ${ }^{1,2,6,7}$. However, although extremely rare, the malignant transformation to squamous cell carcinoma have been described in spinal dermoids ${ }^{17}$. In the case presented, the microscopically total resection of the extramedullary tumor was accomplished with normal nervous margins and the intramedullary conus tumor was totally resected by aspiration with the ultrasonic aspirator after obtaining a small fragment for pathological analysis, minimizing the spinal cord damage to the surgical approach. Taking account the risks of neurological deterioration after gross tumor resection in lesions that are adhered in nervous tissue, complete removal should be performed if possible. Bristow et al. ${ }^{18}$ reported the use of postoperative radiation therapy in the tumor recurrence. They suggest that radiation thera- 
py might have an effect in preventing future cystic re-accumulation in partial resections and may be an alternative to surgery in tumor recurrences ${ }^{18}$.

In conclusion, spinal dermoid cysts are rare tumors that results from congenital or adquired implantation of embriogenic cells in the spinal canal. Although the most common spinal localization is in the lumbosacral region, a concomitance of two separated tumors had never been reported in the literature on the best of our knowledgment. We cannot affirm about what is the origin of the two tumors in the presented case, it might have developed from two different embriogenic cells in the fetal development or might have been secondary to a possible past cyst rupture with spread of the content to the conus medullaris. If possible, total tumor removal should be performed for preventing cystic recurrence and future malignization. However, subtotal extirpation is a reasonable treatment when the tumor is tightly adhered to the nervous tissue which carries much risk of neurological deterioration with gross tumor removal.

ACKNOWLEDGMENT - We thank Dra Karina Salgado for the histopathological investigation.

\section{REFERENCES}

1. Arseni C, Danaila L, Constantinescu A, Carp N. Spinal dermoid tumours. Neurochirurgia (Stuttg) 1977;20:108-116.

2. Bailey IC. Dermoid tumors of the spinal cord. J Neurosurg 1970;33:676-681

3. Calabro F, Capellini C, Jinkins JR. Rupture of spinal dermoid tumors with spread of fatty droplets in the cerebrospinal fluid pathways. Neuroradiology 2000;42:572-579.

4. Fontenelle O Filho, Duarte F. [Intraspinal dermoid and epidermoid tumors]. Arq Neuropsiquiatr 1971;29:26-48.

5. Garg A, Gupta V, Gaikwad S, et al. Isolated central canal rupture of spinal dermoid: report of two cases. Australas Radiol 2003;47:194-197.
6. Guidetti B, Gagliardi FM. Epidermoid and dermoid cysts: clinical evaluation and late surgical results. J Neurosurg 1977;47: 12-18.

7. Lunardi P, Missori P, Gagliardi FM, Fortuna A. Long-term results of the surgical treatment of spinal dermoid and epidermoid tumors. Neurosurgery 1989;25:860-864.

8. Falavigna A, Segatto AC, Salgado K. A rare case of intramedullary lipoma associated with cyst. Arq Neuropsiquiatr 2001; 59:112-115.

9. Mathew P, Todd NV. Intradural conus and cauda equina tumours: a retrospective review of presentation, diagnosis and early outcome. J Neurol Neurosurg Psychiatry 1993;56:69-74.

10. von Bostroem E. Ueber die pialen epidermoide, dermoide and duralen dermoide. Zentbl allg Path Anat 1897;8:1-98.

11. Holmdahl DE. Die zweifache Bildungsweise des Zentralen Nervensystems bei den Wir beltieren. Arch Entwmech Org 1933;129:206-254.

12. Slooff JL. Primary intramedullary tumors of the spinal cord and fillum terminale. Philadelphia: Saunders; 1964.

13. Van Gilder JC, Schwartz HG. Growth of dermoids from skin implants to the nervous system and surrounding spaces of the newborn rat. J Neurosurg 1967;26:14-20.

14. Smith CM, Timperley WR. Multiple intraspinal and intracranial epidermoids and lipomata following gunshot injury. Neuropathol Appl Neurobiol 1984;10:235-239.

15. Choremis C, Economos D, Gargoulas A, Papadatos C. Intraspinal epidermoid tumours (cholesteatomas) in patients treated for tuberculous meningitis. Lancet 1956;271:437-439.

16. Scott RM, Wolpert SM, Bartoshesky LE, Zimbler S, Klauber GT. Dermoid tumors occurring at the site of previous myelomeningocele repair. J Neurosurg 1986;65:779-783.

17. Kudo N, Hasegawa K, Ogose A, et al. Malignant transformation of a lumbar intradural dermoid cyst. J Orthop Sci 2007; 12:300-302.

18. Bristow RG, Laperriere NJ, Tator C, Milosevic M, Wong CS. Post-operative radiotherapy for recurrent dermoid cysts of the spine: a report of 3 cases. J Neurooncol 1997;33:251-256. 